\title{
Silagem de milho ou de cana-de-açúcar com Lactobacillus buchneri exclusivamente ou em associação com $L$. plantarum
}

\author{
Adir de Sá Neto(1), Luiz Gustavo Nussio(1), Maity Zopollatto(1), Daniel Junges(1) e Álvaro Wosniak Bispo(1) \\ (1)Universidade de São Paulo, Escola Superior de Agricultura Luiz de Queiroz, Departamento de Zootecnia, Avenida Pádua Dias, \\ no 11, CEP 13418900 Piracicaba, SP. Email: adirneto@hotmail.com, nussio@usp.br, mzopolla@yahoo.com, danieljunges@gmail.com, \\ alvaro_wb@yahoo.com.br
}

\begin{abstract}
Resumo - O objetivo deste trabalho foi avaliar o efeito de Lactobacillus buchneri aplicado exclusivamente ou em combinação com L. plantarum no perfil fermentativo, na estabilidade aeróbia e no valor nutritivo de silagens de milho e de cana-de-açúcar. O delineamento experimental inteiramente casualizado foi utilizado com quatro repetições. Os tratamentos de silagem de milho foram: controle, sem adição de lactobacilos; $1 \times 10^{5} \mathrm{ufc}^{-1} \mathrm{de}$ L. buchneri; e $1 \times 10^{5}$ ufc $^{-1}$ de L. buchneri e L. plantarum. Na silagem de cana-de-açúcar, os tratamentos foram: controle; e adição de $1 \times 10^{5} \mathrm{ufc} \mathrm{g}^{-1}$ de L. buchneri. As silagens foram armazenadas por 150 dias. $\mathrm{O}$ tratamento das silagens de milho não afetou a maioria das variáveis relacionadas ao valor nutritivo, às características fermentativas, aos perfis microbiológicos, às perdas e à estabilidade aeróbia. Nas silagens de cana-de-açúcar, o tratamento com $L$. buchneri apresentou maior teor de matéria seca, sem apresentar diferenças para as variáveis de valor nutritivo. Além disso, foram observados outros resultados típicos da adição de L. buchneri: menor perda total de matéria seca e menores perdas devidas à produção de gases. A aplicação exclusiva de L. buchneri ou em associação a $L$. plantarum não altera a qualidade e a eficiência de conservação das silagens de milho. Contudo, nas silagens de cana-de-açúcar, a aplicação exclusiva de L. buchneri reduz as perdas de conservação.
\end{abstract}

Termos para indexação: cana-de-açúcar, conservação de forragem, deterioração aeróbia, inoculante, milho.

\section{Corn and sugarcane silages with Lactobacillus buchneri alone or associated with $L$. plantarum}

\begin{abstract}
The objective of this work was to evaluate the effect of Lactobacillus buchneri applied alone or associated with $L$. plantarum on the fermentation profile, aerobic stability, and nutritive value of corn and sugarcane silages. A completely randomized experimental design was used with four replicates. Treatments for corn silage were: a control without lactobacilli; $1 \times 10^{5} \mathrm{cfu} \mathrm{g}^{-1}$ of L. buchneri; and $1 \times 10^{5} \mathrm{cfu} \mathrm{g}^{-1}$ of L. buchneri and L. plantarum. For sugarcane silage, treatments were: a control; and $1 \times 10^{5} \mathrm{cfu}^{-1}$ of $L$. buchneri. Silages were stored for 150 days. Corn silage treatment did not affect most of the variables related to nutritive value, fermentative parameters, microbiological profiles, losses, and aerobic stability. In sugarcane silages, treatment with L. buchneri showed a higher dry matter content, with no differences for the other nutritive value variables. Furthermore, other typical results regarding L. buchneri addition were observed: lower total dry matter loss and lower losses due to gas production. Addition of L. buchneri, alone or associated with L. plantarum, does not change quality and conservation efficiency in corn silages. However, in sugarcane silages the application of $L$. buchneri decreases conservation losses.
\end{abstract}

Index terms: sugarcane, forage conservation, aerobic deterioration, inoculant, corn.

\section{Introdução}

O uso de combinações de bactérias homoláticas e heteroláticas tem sido estudado em silagens de milho, trigo, alfafa e gramineas forrageiras, a fim de se aliar o efeito positivo das homoláticas na fermentação decorrente do rápido abaixamento do $\mathrm{pH}$, causado pela elevada produção de ácido lático, e as vantagens das bactérias heteroláticas após a abertura, em razão da produção de ácido acético, eficiente no controle de fungos e leveduras (Hu et al., 2009; Queiroz et al., 2012).

No Brasil, a produção de cana-de-açúcar é elevada, e sua ensilagem representa alternativa ao processo de corte diário para fornecimento do material in natura. No entanto, ao se considerar a possibilidade de ensilagem da cana-de-açúcar, deve-se levar em conta que esta apresenta fermentação tipicamente alcoólica, em consequência da intensa atividade de leveduras que convertem os açúcares da forragem a etanol, $\mathrm{CO}_{2} \mathrm{e}$ 
água. Teores de etanol de 8 a 17\% da matéria seca (MS) têm sido relatados em cana-de-açúcar ensilada sem o uso de aditivos, acompanhados por perdas gasosas de até 15,9\% da MS (Pedroso et al., 2005; Siqueira et al., 2007) e perdas totais de MS de até 32,5\% (Siqueira et al., 2007). Este tipo de fermentação pode causar reduções de 44 a $68 \%$ no teor de açúcares, aumento relativo nos componentes da parede celular e redução de $28 \%$ na digestibilidade da cana-de-açúcar assim conservada (Pedroso et al., 2005).

$\mathrm{O}$ uso de aditivos à base de bactérias heteroláticas tem sido eficiente para controlar a população de leveduras, o que reduz a fermentação alcoólica na massa ensilada e melhora a estabilidade aeróbia, tanto em silagens de milho (Nishino et al., 2004; Tabacco et al., 2011), quanto de cana-de-açúcar (Siqueira et al., 2007; Mendes et al., 2008; Ávila et al., 2012). Silagens de cana-de-açúcar adicionadas de L. buchneri têm mostrado redução de $50 \%$ na produção de etanol (1,9 vs. $4,1 \%$ da MS), $17 \%$ na perda de gases, $56 \%$ na perda total de MS e aumento de $64 \%$ na estabilidade aeróbia, em relação às silagens sem adição de lactobacilos (Pedroso et al., 2005; Siqueira et al., 2007; Mendes et al., 2008).

O objetivo deste trabalho foi avaliar o efeito de L. buchneri exclusivamente ou em combinação com L. plantarum no perfil fermentativo, estabilidade aeróbia e valor nutritivo de silagens de milho e de cana-de-açúcar.

\section{Material e Métodos}

O experimento foi realizado no Departamento de Zootecnia, da Escola Superior de Agricultura Luiz de Queiroz, da Universidade de São Paulo. Para a ensilagem do milho, utilizou-se o híbrido Pioneer 30F90 Bt. Aos 132 dias após a emergência da planta de milho, com média de 36,9\% de MS, procedeu-se à ensilagem. A cultivar de cana-de-açúcar utilizada foi a IAC933046, e a ensilagem foi realizada quando a maturação atingiu $19,5{ }^{\circ}$ Brix e $26,4 \%$ de matéria seca. As plantas de milho e de cana-de-açúcar foram colhidas mecanicamente com colhedora tracionada por trator.

Como silos experimentais (unidades experimentais) foram utilizados baldes de plástico, com capacidade de $20 \mathrm{~L}$ e tampas próprias à vedação, adaptadas com válvulas do tipo Bunsen, para a avaliação das perdas gasosas durante a ensilagem. No fundo de cada balde, foram colocados $2 \mathrm{~kg}$ de areia seca, separados da massa de forragem por tela fina de plástico e duas camadas de tecido fino de algodão, para a avaliação quantitativa de efluentes. Durante a ensilagem, os silos foram abastecidos em camadas de 10 a $15 \mathrm{~cm}$ de forragem, compactadas por pisoteio humano até atingir a densidade média de $600 \mathrm{~kg} \mathrm{~m}^{3}$ (Jobim et al., 2007). A abertura foi realizada aos 150 dias de armazenamento.

Foram utilizados dois aditivos, o primeiro foi composto por bactérias da espécie Lactobacillus buchneri (DSM 13573) e o segundo por bactérias da espécie Lactobacillus buchneri e Lactobacillus plantarum (DSM 3676 e DSM 3677). Os lactobacilos foram diluídos em água destilada e pulverizados sobre as respectivas forragens, com uma concentração de $4 \mathrm{~L} \mathrm{Mg}^{-1}$ de forragem fresca.

Os tratamentos utilizados na forragem de milho foram: controle, sem adição de lactobacilos; adição de $10^{5} \mathrm{ufc}^{-1}$ de forragem fresca com L. buchneri; e adição de $10^{5} \mathrm{ufc} \mathrm{g}^{-1}$ de forragem fresca composto de L. buchneri e L. plantarum.

$\mathrm{Na}$ cana-de-açúcar os tratamentos utilizados foram: controle, sem adição de lactobacilos; adição de $10^{5} \mathrm{ufc}^{-1}$ de forragem fresca com L. buchneri. Não foi utilizado $L$. plantarum na cana-de-açúcar, pois alguns estudos mostram que silagens de cana-de-açúcar adicionadas desta bactéria homolática apresentam problemas na fermentação e conservação do material (Pedroso et al., 2008; Ávila et al., 2010). Durante a ensilagem, as forragens foram amostradas para posterior análise. As amostras foram secas em estufa de ventilação forçada a $55^{\circ} \mathrm{C}$ por 72 horas (Helrich, 1990), e usadas para a determinação do teor de MS em estufa a $105^{\circ} \mathrm{C}$, durante 12 horas. O conteúdo de matéria mineral (MM) foi determinado após a incineração das amostras em forno tipo mufla a $550^{\circ} \mathrm{C}$, durante três horas (Helrich, 1990).

A determinação da composição bromatológica das forragens foi realizada pelo método de espectroscopia de reflectância de infravermelho próximo (NIRS) (Berzaghi et al., 1997). O material moído foi escaneado para obtenção dos espectros. O equipamento utilizado foi o espectrômetro NIRS 5000 (NIRSystems, Silver Spring, MD, EUA), acoplado a um microcomputador equipado com programa WinISI II versão 6.2 (Intrasoft International, PA, EUA). Das amostras escaneadas 
obtiveram-se as seguintes variáveis para as forragens avaliadas: fibra insolúvel em detergente ácido (FDA); fibra insolúvel em detergente neutro (FDN); proteína bruta (PB); e digestibilidade verdadeira in vitro da matéria seca (DVIVMS). Das amostras de milho obteve-se, além das variáveis já descritas, valores de extrato etéreo (EE), celulose e amido.

No momento da abertura, os silos foram pesados para avaliar o efeito dos tratamentos quanto às perdas de MS total, produção de gases e produção de efluente. Para que fosse possível a determinação das perdas, o conjunto vazio (balde + areia + tampa + tela + pano) foi pesado antes da ensilagem e, imediatamente após a abertura. Com o mesmo procedimento, esse conjunto, que continha a forragem, também foi pesado nesses mesmos dois momentos (Jobim et al., 2007).

No preparo do extrato aquoso, uma alíquota de $25 \mathrm{~g}$ de amostra fresca foi pesada em saco de plástico e diluída em $225 \mathrm{~mL}$ de água deionizada (Kung Junior \& Ranjit, 2001), seguida de homogeneização durante 4 min, a 150 rpm, em aparelho LabBlender Stomacher 400 (Steward Laboratory, Londres, Inglaterra). Uma amostra dos extratos foi usada nas análises microbiológicas, e o restante armazenado em tubos de Eppendorf, em freezer a $20^{\circ} \mathrm{C}$, para futuras análises de ácido lático e ácidos graxos voláteis.

Nas avaliações microbiológicas, os extratos aquosos foram submetidos a diluições decimais em solução Ringer a $25 \%$ e plaqueados em placas $3 \mathrm{M}$ Petrifilm. Para a contagem de bactérias acidoláticas (LAB) foi utilizado o Petrifilm AC. Os petrifilmes foram incubados a $32^{\circ} \mathrm{C}$ por 48 horas em jarras de anaerobiose. Para a contagem de fungos e leveduras utilizou-se o Petrifilm YM. Os microrganismos foram incubados a $25^{\circ} \mathrm{C}$ por 72 horas, para a contagem de leveduras, e foram mantidos até 120 horas para a contagem de fungos. Os números de microrganismos presentes foram contados como unidade formadora de colônia e expressos como logaritmo na base 10 .

Para a análise dos ácidos graxos voláteis (ácido acético e ácido butírico), a leitura foi realizada em cromatógrafo líquido gasoso Hewlett Packard 5890, series II (Hewlett Packard Company, Avondale, PA). A determinação da concentração de ácido lático foi realizada por meio da adaptação do método espectrofotométrico (565 nm) de Pryce (1969).

Para o ensaio de estabilidade aeróbia, cerca de $4 \mathrm{~kg}$ de silagem foram acomodados, sem compactação, em baldes de plástico sem tampa com capacidade de $20 \mathrm{~L}$ cada, que foram mantidos em ambiente protegido, à temperatura controlada $\left(23 \pm 1^{\circ} \mathrm{C}\right)$ por 240 horas (10 dias). No centro geométrico do balde, foi acondicionado um sensor de temperatura, associado a um sistema informatizado e eletrônico de aquisição de dados (Chiplog, Impac, EUA), programado para leitura da temperatura da massa a intervalos constantes de $15 \mathrm{~min}$.

$\mathrm{Na}$ determinação da estabilidade aeróbia foram estudadas as seguintes variáveis: Tmáx, temperatura máxima alcançada $\left({ }^{\circ} \mathrm{C}\right)$; TTmáx, tempo para alcançar a temperatura máxima (horas); perda de estabilidade, tempo necessário para a temperatura da silagem atingir $2{ }^{\circ} \mathrm{C}$ acima da temperatura ambiente (horas); AC5, acúmulo de temperatura da amostra, em relação à temperatura ambiente, durante cinco dias de exposição aeróbia $\left({ }^{\circ} \mathrm{C}\right)$; e $\mathrm{AC} 10$, acúmulo de temperatura da amostra em relação à temperatura ambiente durante dez dias de exposição aeróbia $\left({ }^{\circ} \mathrm{C}\right)$.

$\mathrm{O}$ delineamento experimental inteiramente casualizado foi utilizado com quatro repetições. Para a ensilagem da cultura do milho, foram estabelecidos três tratamentos que totalizaram 12 unidades experimentais. Com a cultura de cana-de-açúcar, foram estabelecidos dois tratamentos que totalizaram oito unidades experimentais.

Os dados foram submetidos à análise de variância e suas médias foram comparadas separadamente em cada cultura, pelo teste de Tukey a $5 \%$ de probabilidade, com uso do procedimento Mixed do programa SAS.

\section{Resultados e Discussão}

As forragens de milho apresentaram teor médio de matéria seca de $37,6 \%$. As concentrações de FDN variaram de $49,1 \%$ no tratamento controle a $52,3 \%$ no tratamento com os lactobacilos. No momento da ensilagem, verificou-se que a população média de leveduras e de fungos foi de 6,65 e de 5,76 log ufc g-1 de forragem, respectivamente. A forragem do tratamento com os dois lactobacilos apresentou população superior de bactérias acidoláticas, com diferença de $2 \log$ ufc g-1 de forragem fresca.

O tratamento das silagens com L. buchneri, exclusivamente, ou associado a $L$. plantarum, não afetou as variáveis relacionadas ao valor nutritivo das silagens de milho, após 150 dias de armazenamento 
(Tabela 1). A matéria seca média reduziu-se após a estocagem, de $37,6 \%$, durante a ensilagem, para $35,6 \%$ após a abertura. Durante a ensilagem do milho, a população de bactérias acidoláticas, no tratamento controle, foi de 7,46 log ufc $\mathrm{g}^{-1}$, enquanto a contagem no tratamento com L. buchneri, após colocar-se o aditivo, foi de 7,17 log ufc $\mathrm{g}^{-1}$. Esperava-se que as contagens de bactérias acidoláticas se elevassem após a aplicação dos lactobacilos, em silagens de milho, fato que ocorreu somente no tratamento com L. buchneri + L. plantarum, em que a população de bactérias acidoláticas na forragem fresca foi de 9,46 log ufc g-1.

Após os 150 dias de armazenamento, não foram detectadas diferenças significativas quanto às populações de bactérias acidoláticas entre os tratamentos com L. buchneri + L. plantarum, L. buchneri e controle nas silagens de milho (Tabela 2). As contagens de leveduras foram, em média, 4,77 log ufc $\mathrm{g}^{-1} \mathrm{de}$ silagem, e não foram detectados fungos nas amostras decorrentes das diluições utilizadas. A população de fungos foi inferior a $3 \log$ ufc $\mathrm{g}^{-1}$.

Os valores de $\mathrm{pH}$ das silagens de milho variaram de 3,70, no tratamento com L. buchneri + L. plantarum, a 3,79 no tratamento só com L. buchneri. As silagens do tratamento controle apresentaram maiores concentrações de ácido acético, em comparação ao tratamento com L. buchneri, enquanto as silagens do tratamento com L. buchneri + L. plantarum tiveram valores intermediários. Esses resultados são contrários

Tabela 1. Valor nutritivo de silagens de milho adicionadas de Lactobacillus buchneri (LB) isolado ou associado ao L. plantarum (LP).

\begin{tabular}{lccccc}
\hline Variável $^{(1)}$ & \multicolumn{3}{c}{ Tratamento } & EPM & Efeito \\
\cline { 2 - 4 } & Controle & LB & LB+LP & & \\
\hline MS (\%) & 34,87 & 36,71 & 35,12 & 0,96 & 0,171 \\
MM (\% MS) & 4,04 & 4,39 & 4,52 & 0,21 & 0,297 \\
EE (\% MS) & 2,23 & 2,37 & 2,29 & 0,12 & 0,748 \\
PB (\% MS) & 7,35 & 7,16 & 7,66 & 0,16 & 0,131 \\
FDN (\% MS) & 53,4 & 51,9 & 50,37 & 0,9 & 0,113 \\
FDA (\% MS) & 35,01 & 33,99 & 33,38 & 0,65 & 0,250 \\
Celulose (\% MS) & 27,64 & 26,58 & 25,97 & 0,61 & 0,207 \\
Hemicelulose (\% MS) & 20,39 & 20,14 & 18,85 & 0,49 & 0,108 \\
Amido (\% MS) & 23,81 & 25,96 & 26,42 & 1,17 & 0,290 \\
DVIVMS (\%) & 70,67 & 71,26 & 71,68 & 0,61 & 0,523 \\
\hline
\end{tabular}

${ }^{(1)} \mathrm{MS}$, matéria seca; MM, matéria mineral; EE, extrato etéreo; PB, proteína bruta; FDN, fibra insolúvel em detergente neutro; FDA, fibra insolúvel em detergente ácido; DVIVMS, digestibilidade verdadeira in vitro da matéria seca. EPM, erro-padrão da média. ao esperado com o uso dos lactobacilos. O Lactobacillus buchneri caracteriza-se por apresentar rota metabólica heterolática, com capacidade de produzir ácido acético durante a fermentação e após a abertura do silo, com consequente controle efetivo de leveduras e fungos filamentosos (Kung Junior \& Ranjit, 2001; Filya, 2003; Pahlow et al., 2003).

Em um estudo com silagens de milho, com $21,5 \%$ de MS armazenada por 90 dias, Filya (2003) observou que as silagens tratadas com L. buchneri apresentavam maiores teores de ácido acético e menores concentrações de ácido lático, enquanto as silagens que continham L. buchneri e L. plantarum apresentavam maiores teores de ácido lático e de ácido acético, na comparação ao tratamento controle. Esses aditivos foram efetivos em manter a silagem estável durante o período de exposição aeróbia.

As perdas de MS observadas nas silagens de milho ocorreram em consequência da produção de gases durante o armazenamento, não tendo sido detectada produção de efluentes nessas silagens (Tabela 3). As perdas de MS no presente estudo foram semelhantes

Tabela 2. Características fermentativas e microbiológicas das silagens de milho com inoculação de Lactobacillus buchneri (LB) isolado ou associado ao L. plantarum (LP) ${ }^{(1)}$.

\begin{tabular}{lccccc}
\hline Variável & \multicolumn{3}{c}{ Tratamento } & EPM Efeito \\
\cline { 2 - 5 } & Controle & LB & LB+LP & \\
\hline Bactérias acidoláticas $\left(\log\right.$ ufc g $^{-1}$ ) & 5,32 & 5,65 & 6,23 & 0,27 & 0,112 \\
Levedura (log ufc g $\left.{ }^{-1}\right)$ & 4,63 & 4,84 & 4,83 & 0,09 & 0,254 \\
$\mathrm{pH}$ & 3,76 & 3,79 & 3,70 & 0,04 & 0,365 \\
Ácido acético (\% MS) & $2,30 \mathrm{a}$ & $1,23 \mathrm{~b}$ & $1,50 \mathrm{ab}$ & 0,26 & 0,024 \\
Ácido lático (\% MS) & 2,62 & 4,6 & 4,46 & 0,84 & 0,223 \\
\hline
\end{tabular}

${ }^{(1)}$ Médias seguidas de letras distintas, diferem pelo teste de Tukey, a $5 \%$ de probabilidade. EPM, erro-padrão da média.

Tabela 3. Perdas de matéria seca e variáveis analisadas durante a exposição aeróbia de silagens de milho, com inoculação de Lactobacillus buchneri (LB) isolado ou associado ao L. plantarum (LP).

\begin{tabular}{lccccc}
\hline Variável ${ }^{(1)}$ & \multicolumn{3}{c}{ Tratamento } & EPM & Efeito \\
\cline { 2 - 4 } & Controle & LB & LB+LP & & \\
\hline Perda de MS (\%) & 6,83 & 6,73 & 3,92 & 1,46 & 0,418 \\
Temperatura máxima $\left({ }^{\circ} \mathrm{C}\right)$ & 37,9 & 36,2 & 36,4 & 1,01 & 0,493 \\
Tempo máximo (h) & 144,17 & 161,92 & 142,33 & 10,57 & 0,407 \\
Perda de estabilidade (h) & 65,25 & 66,68 & 60,5 & 3,34 & 0,442 \\
AC5 $\left({ }^{\circ} \mathrm{C}\right)$ & 16,57 & 16,76 & 20,13 & 2,26 & 0,499 \\
AC10 $\left({ }^{\circ} \mathrm{C}\right)$ & 72,21 & 70,38 & 74,13 & 6,5 & 0,910 \\
\hline
\end{tabular}

${ }^{(1)} \mathrm{MS}$, matéria seca; AC5, acúmulo de temperatura durante cinco dias; AC10, acúmulo de temperatura durante dez dias. EPM, erro-padrão da média. 
entre os tratamentos. Ao avaliar silagens adicionadas de L. buchneri e com $29,1 \%$ de MS, Nishino et al. (2004) não observaram diferenças entre o tratamento controle e o aditivo nas perdas de MS durante 60 e 90 dias de armazenamento. As perdas foram de 3,81 e 4,52\% na abertura aos 60 dias e 4,51 e $8,08 \%$ na abertura aos 90 dias, para o tratamento controle e o aditivo, respectivamente.

Com relação às variáveis analisadas durante a exposição aeróbia, os tratamentos não diferiram (Tabela 3). As temperaturas máximas alcançadas foram de $37,9,36,4$ e $36,2^{\circ} \mathrm{C}$, no tratamento controle, no L. buchneri + L. plantarum e no L. buchneri, respectivamente. Todas as silagens ultrapassaram a temperatura ambiente em $2^{\circ} \mathrm{C}$, após 60 horas de exposição aeróbia.

Os dados observados no presente experimento corroboram os de Muck (2004), que avaliou silagens de milho produzidas durante três anos consecutivos, com três diferentes aditivos que continham exclusivamente L. buchneri, e observou que L. buchneri não melhorou a estabilidade aeróbia, quando a diferença entre a população epífita de bactérias acidoláticas e a dose de lactobacilos utilizada foi menor do que 1,5 log ufc g-1.

Ao avaliar a adição de L. buchneri, de forma exclusiva ou combinada com L. plantarum, $\mathrm{Hu}$ et al. (2009) observaram maior produção de ácido acético nas silagens com inoculação em comparação ao tratamento controle. Em razão disso, essas silagens foram mais estáveis durante a fase de exposição aeróbia.

Provavelmente, a falta de respostas positivas observadas no presente estudo pode estar relacionada ao alto teor de matéria seca das plantas de milho utilizadas $(37,6 \%)$, o que também resultou na ausência de efluentes. Hu et al. (2009) avaliaram a influência dos teores de 33,1 e 40,6\% de MS da silagem após 240 dias de armazenamento, e observaram que, com o aumento dos teores de matéria seca, houve acréscimo nos valores de $\mathrm{pH}$, nas concentrações de etanol e nas contagens de leveduras de todos tratamentos. Segundo os autores, os maiores teores de matéria seca influenciaram negativamente a eficácia dos aditivos. O Lactobacillus plantarum produziu menores concentrações de ácido lático e sua combinação com L. buchneri também diminuiu as concentrações de ácidos produzidos (acético e lático).

No experimento com cana-de-açúcar, no momento da ensilagem, a planta apresentou $21,4{ }^{\circ}$ Brix e
$26,4 \%$ de MS, 3,1\% de proteína e $64,7 \%$ de FDN. A população epifítica de leveduras e fungos encontrada na cana-de-açúcar foi de, respectivamente, 5,24 e 5,22 log ufc $\mathrm{g}^{-1}$ de forragem fresca. A população de bactérias acidoláticas mensurada após adição à forragem foi de 6,23 log ufc g ${ }^{-1}$, na forragem adicionada de bactérias acidoláticas, enquanto na forragem do tratamento controle foi de $6,11 \log$ ufc g $^{-1}$ de forragem fresca.

As silagens de cana-de-açúcar dos tratamentos controle e L. buchneri apresentaram em relação à forragem fresca maiores valores de FDA, FDN e PB (Tabela 4). O efeito inverso ocorreu nos teores de MS, em que se observou redução destes em relação à forragem fresca, que foram de $15 \%$ no tratamento controle e de 10\% nas silagens do tratamento L. buchneri. Em consequência dessas reduções nos teores de MS, quando foram comparadas as concentrações dos demais parâmetros bromatológicos, durante a ensilagem e no momento da abertura dos silos, observou-se acréscimo das concentrações de MM, PB, FDN e FDA. Esses resultados também foram relatados por Pedroso et al. (2005), Freitas et al. (2006) e Sousa et al. (2008). Em silagens, a fração fibrosa pode aumentar percentualmente na MS, em consequência da produção de efluentes, uma vez que os componentes solúveis em água são perdidos proporcionalmente ao aumento da fração menos fermentável e insolúvel (Loures et al., 2005), particularmente os constituintes da parede celular, que ficam retidos na silagem.

As silagens do tratamento L. buchneri apresentaram maiores $(p<0,05)$ teores de MS em comparação ao controle (Tabela 4). Não foram observadas diferenças quanto às variáveis, MM, PB, FDN, FDA e DVIVMS.

Tabela 4. Valor nutritivo de silagens de cana-de-açúcar com inoculação de Lactobacillus buchneri (LB) no momento da abertura dos silos.

\begin{tabular}{lcccc}
\hline Variável $^{(1)}$ & Controle & LB & EPM & Probabilidade \\
\hline MS (\%) & 22,34 & 23,7 & 0,2 & 0,002 \\
MM (\% MS) & 7,22 & 7,01 & 0,21 & 0,51 \\
PB (\% MS) & 3,55 & 3,47 & 0,06 & 0,33 \\
FDN (\% MS) & 71,47 & 70,75 & 0,81 & 0,55 \\
FDA (\% MS) & 49,91 & 49,19 & 0,49 & 0,338 \\
DVIVMS (\%) & 45,97 & 46,26 & 0,38 & 0,599 \\
\hline
\end{tabular}

${ }^{(1)} \mathrm{MS}$, matéria seca; MM, matéria mineral; $\mathrm{PB}$, proteína bruta; FDN, fibra insolúvel em detergente neutro; FDA, fibra insolúvel em detergente ácido; DVIVMS, digestibilidade verdadeira in vitro da matéria seca. EPM, erro-padrão da média. 
$\mathrm{Na}$ comparação das características fermentativas e microbiológicas das silagens de cana-de-açúcar, após 90 dias de armazenamento, observou-se que nas silagens do tratamento controle houve maior população de bactérias acidoláticas do que no tratamento com L. buchneri (Tabela 5).

Populações de bactérias acidoláticas de 7,72 e $6,9 \log$ ufc $\mathrm{g}^{-1}$ de forragem, respectivamente, na silagen controle e tratada com L. buchneri foram encontradas por Carvalho et al. (2012). Os resultados encontrados no presente estudo corroboram os desses autores, uma vez que a população de bactérias acidoláticas no tratamento controle foi superior à do tratamento L. buchneri (Tabela 5). Ávila et al. (2009) encontraram populações indígenas de L. buchneri em uma prospecção de bactérias acidoláticas em silagens de cana-de-açúcar. Após o isolamento dessas bactérias e sua adição a silagens de cana-de-açúcar, percebeu-se que essas populações foram tão efetivas na produção de ácido acético quanto as populações provenientes do aditivo comercial.

$\mathrm{O}$ menor valor de $\mathrm{pH}$ foi observado nas silagens do tratamento controle. Schmidt et al. (2007) também observaram maiores valores de $\mathrm{pH}$ nas silagens tratadas com $3,6 \times 10^{5}$ ufc g ${ }^{-1}$ de L. buchneri $(3,46)$ em comparação à silagem controle $(3,31)$, após 90 dias de armazenamento.

Não foram detectadas diferenças na produção de ácido acético entre os tratamentos, e a silagem controle também apresentou altas concentrações de MS (5,7\%). Pedroso et al. (2011) avaliaram a produção de ácido acético em silagens de cana-deaçúcar com L. buchneri e também não encontraram diferenças entre os tratamentos, que tiveram valores de $6,75 \%$ MS no tratamento controle e $8,51 \%$ MS nas silagens adicionadas de $5 \times 10^{4}$ ufc $\mathrm{g}^{-1}$ de L. buchneri. No mesmo sentido, Carvalho et al. (2012) observaram

Tabela 5. Características fermentativas e microbiológicas de silagens de cana-de-açúcar, com inoculação de Lactobacillus buchneri (LB).

\begin{tabular}{lcccc}
\hline Variável & Controle & LB & EPM & $p$ \\
\hline Bactérias acidoláticas $\left(\log \mathrm{ufc} \mathrm{g}^{-1}\right)$ & 6,96 & 6,36 & 0,06 & $<0,001$ \\
Levedura $\left(\log \mathrm{ufc}^{-1}\right)$ & 2,47 & 2,77 & 0,34 & 0,56 \\
$\mathrm{pH}$ & 3,43 & 3,56 & 0,03 & 0,009 \\
Ácido acético (\% MS) & 5,7 & 5,3 & 0,48 & 0,576 \\
Ácido lático (\% MS) & 6,07 & 4,52 & 0,56 & 0,1 \\
\hline
\end{tabular}

EPM, erro-padrão da média; $p$, probabilidade. teor de ácido acético de 5,10\% MS nas silagens de cana-de-açúcar do tratamento controle, após 170 dias de armazenamento e, provavelmente, em razão das concentrações de ácido acético nos tratamentos controle e L. buchneri, não observaram diferenças na população de leveduras, que apresentaram contagem média de 2,62 log ufc $\mathrm{g}^{-1}$ de silagem.

As perdas de MS e de gases nas silagens do tratamento com L. buchneri foram inferiores às das silagens do tratamento controle (Tabela 6) e não foram observadas diferenças entre os tratamentos na produção de efluentes. Siqueira et al. (2010) estudaram o efeito de $5 \times 10^{4}$ ufc $^{-1}$ de L. buchneri em silagens de cana-de-açúcar com 35,3\% MS, e também observaram maiores produções de gases e perda de matéria seca no tratamento controle (de 17,0 para 12,2\% MS e de 31,0 para $16,0 \%$, respectivamente). Entretanto, com relação às variáveis mensuradas durante a exposição aeróbia, as silagens do tratamento controle foram superiores. A silagem no tratamento controle atingiu o pico de temperatura depois da silagem com L. buchneri, e a temperatura máxima observada foi superior na silagem aditivada. Além disso, observou-se menor acúmulo de temperatura até o quinto dia de exposição aeróbia no tratamento controle.

Os resultados da adição de L. buchneri a silagens de cana-de-açúcar têm sido variáveis. Vários estudos foram realizados e respostas positivas foram observadas, como a melhoria na estabilidade aeróbia e a redução na contagem de leveduras, nas silagens de cana-de-açúcar adicionadas de L. buchneri (Siqueira et al., 2007; Mendes et al., 2008), enquanto outros estudos não detectaram essas diferenças (Freitas et al.,

Tabela 6. Perdas de matéria seca e variáveis analisadas, durante a exposição aeróbia de silagens de cana-de-açúcar com inoculação de Lactobacillus buchneri (LB).

\begin{tabular}{lcccc}
\hline Variável $^{(1)}$ & Controle & LB & EPM & $\mathrm{p}$ \\
\hline Perda MS (\%) & 20,28 & 15,89 & 0,79 & 0,008 \\
Gases $(\% \mathrm{MS})$ & 17,53 & 12,46 & 0,77 & 0,003 \\
Efluente $\left(\mathrm{kg} \mathrm{t}^{-1} \mathrm{MV}\right)$ & 32,35 & 38,39 & 2,43 & 0,130 \\
Temperatura máxima $\left({ }^{\circ} \mathrm{C}\right)$ & 39,30 & 41 & 0,39 & 0,026 \\
Tempo máximo $(\mathrm{h})$ & 137,12 & 94,67 & 6,53 & 0,006 \\
Perda de estabilidade $(\mathrm{h})$ & 68,25 & 57,92 & 3,04 & 0,061 \\
AC5 $\left({ }^{\circ} \mathrm{C}\right)$ & 23,20 & 35 & 2,77 & 0,029 \\
AC10 $\left({ }^{\circ} \mathrm{C}\right)$ & 70,30 & 70 & 2,33 & 0,935 \\
\hline
\end{tabular}

${ }^{(1)} \mathrm{MS}$, matéria seca; MV, matéria verde; AC5, acúmulo de temperatura durante cinco dias; AC10, acúmulo de temperatura durante dez dias. EPM, erro-padrão da média; $p$, probabilidade.

Pesq. agropec. bras., Brasília, v.48, n.5, p.528-535, maio 2013 DOI: $10.1590 / \mathrm{S} 0100-204 \mathrm{X} 2013000500009$ 
2006; Siqueira et al., 2010). Segundo Schmidt (2008), a variabilidade do padrão de respostas à aplicação de lactobacilos parece ser superior à de outros aditivos, possivelmente, porque muitos fatores podem afetar o desenvolvimento dos microrganismos, como população epifítica, temperatura da silagem, ambiente, composição de carboidratos, entre outros.

\section{Conclusão}

A aplicação exclusiva de Lactobacillus buchneri ou em associação a $L$. plantarum não altera a qualidade e a eficiência de conservação das silagens de milho; contudo, nas silagens de cana-de-açúcar, a aplicação exclusiva de L. buchneri reduz as perdas de conservação.

\section{Referências}

ÁVILA, C.L.S.; PINTO, J.C.; FIGUEIREDO, H.C.P.; SCHWAN, R.F. Effects of an indigenous and a commercial Lactobacillus buchneri strain on quality of sugar cane silage. Grass and Forage Science, v.64, p.384-394, 2009. DOI: 10.1111/j.13652494.2009.00703.x.

ÁVILA, C.L. da S.; PINTO, J.C.; OLIVEIRA, D.P.; SCHWAN, R.F. Aerobic stability of sugar cane silages with a novel strain of Lactobacillus sp. isolated from sugar cane. Revista Brasileira de Zootecnia, v.41, p.249-255, 2012. DOI: 10.1590/S151635982012000200003 .

ÁVILA, C.L. da S.; VALERIANO, A.R.; PINTO, J.C.; FIGUEIREDO, H.C.P.; REZENDE, A.V. de; SCHWAN, R.F. Chemical and microbiological characteristics of sugar cane silages treated with microbial inoculants. Revista Brasileira de Zootecnia, v.39, p.25-32, 2010. DOI: 10.1590/S1516-35982010000100004.

BERZAGHI, P.; COZZI, G.; ANDRIGHETTO, I. The use of near infrared analysis for in situ studies. Journal of Dairy Science, v.80, p.3263-3270, 1997. DOI: 10.3168/jds.S0022-0302(97)76301-X.

CARVALHO, B.F.; ÁVILA, C.L.S.; PINTO, J.C.; PEREIRA, M.N.; SCHWAN, R.F. Effects of propionic acid and Lactobacillus buchneri (UFLA SIL 72) addition on fermentative and microbiological characteristics of sugar cane silage treated with and without calcium oxide. Grass and Forage Science, v.67, p.462-471, 2012. DOI: 10.1111/j.1365-2494.2012.00863.x.

FILYA, I. The Effect of Lactobacillus buchneri and Lactobacillus plantarum on the fermentation, aerobic stability, and ruminal degradability of low dry matter corn and sorghum silages. Journal of Dairy Science, v.86, p.3575-3581, 2003. DOI: 10.3168/jds. S0022-0302(03)73963-0.

FREITAS, A.W. de P.F.; PEREIRA, J.C.; ROCHA, F.C.; COSTA M.G.; LEONEL, F. de P.; RIBEIRO, M.D. Avaliação da qualidade nutricional da silagem de cana-de-açúcar com aditivos microbianos e enriquecida com resíduos da colheita da soja. Revista Brasileira de Zootecnia, v.35, p.38-47, 2006. DOI: 10.1590/S151635982006000100005 .

HELRICH, K. Official methods of analysis of the Association of Official Analytical Chemists. Arlington: AOAC, 1990. 2v.

HU, W.; SCHMIDT, R.J.; MCDONELL, E.E.; KLINGERMAN, C.M.; KUNG JUNIOR, L. The effect of Lactobacillus buchneri 40788 or Lactobacillus plantarum MTD1 on the fermentation and aerobic stability of corn silages ensiled at two dry matter contents. Journal of Dairy Science, v.92, p.3907-3914, 2009. DOI: 10.3168/ jds.2008-1788.

JOBIM, C.C.; NUSSIO, L.G.; REIS, R.A.; SCHMIDT, P. Avanços metodológicos na avaliação da qualidade da forragem conservada.

Revista Brasileira de Zootecnia, v.36, p.101-119, 2007. DOI: 10.1590/S1516-35982007001000013.

KUNG JUNIOR, L.; RANJIT, N.K. The effect of Lactobacillus buchneri and other additives on the fermentation and aerobic stability of barley silage. Journal of Dairy Science, v.84, p.11491155, 2001. DOI: 10.3168/jds.S0022-0302(01)74575-4.

LOURES, D.R.S.; NUSSIO, L.G.; PAZIANI, S. de F.; PEDROSO, A. de F.; MARI, L.J.; RIBEIRO, J.L.; ZOPOLLATTO, M.; SCHMIDT, P.; JUNQUEIRA, M.C.; PACKER, I.U.; CAMPOS, F.P. Composição bromatológica e produção de efluente de silagens de capimtanzânia sob efeitos do emurchecimento, do tamanho de partícula e do uso de aditivos biológicos. Revista Brasileira de Zootecnia, v.34, p.726-735, 2005. DOI: 10.1590/S151635982005000300003 .

MENDES, C.Q.; SUSIN, I.; NUSSIO, L.G.; PIRES, A.V.; RODRIGUES, G.H.; URANO, F.S. Efeito do Lactobacillus buchneri na fermentação, estabilidade aeróbia e no valor nutritivo de silagem de cana-de-açúcar. Revista Brasileira de Zootecnia, v.37, p.2191-2198, 2008. DOI: 10.1590/S1516-35982008001200017.

MUCK, R.E. Effects of corn silage inoculants on aerobic stability. Transactions of the ASAE, v.47, p.1011-1016, 2004.

NISHINO, N.; WADA, H.; YOSHIDA, M.; SHIOTA, H. Microbial counts, fermentation products, and aerobic stability of whole crop corn and a total mixed ration ensiled with and without inoculation of Lactobacillus casei or Lactobacillus buchneri. Journal of Dairy Science, v.87, p.2563-2570, 2004. DOI: 10.3168/jds.S00220302(04)73381-0.

PAHLOW, G.; MUCK, R.E.; DRIEHUIS, F.; OUDE ELFERINK, S.J.W.H.; SPOELSTRA, S.F. Microbiology of ensiling. In: BUXTON, D.R.; MUCK, R.E.; HARRISON, J.H. (Ed.). Silage science and technology. Madison: American Society of Agronomy, 2003. p.31-94.

PEDROSO, A. de F.; NUSSIO, L.G.; LOURES, D.R.S.; PAZIANI, S. de F.; RIBEIRO, J.L.; MARI, L.J.; ZOPOLLATTO, M.; SCHMIDT, P.; MATTOS, W.R.S.; HORII, J. Fermentation, losses, and aerobic stability of sugarcane silages treated with chemical or bacterial additives. Scientia Agricola, v.65, p.567-691, 2008. DOI: 10.1590/S0103-90162008000600004.

PEDROSO, A. de F.; NUSSIO, L.G.; PAZIANI, S. de F.; LOURES, D.R.S; IGARASI, M.S.; COELHO, R.M; PACKER I.H.; HORI, J; GOMES, L.H. Fermentation and epiphytic microflora dynamics in sugar cane silage. Scientia Agricola, v.62, p.427-432, 2005. DOI: 10.1590/S0103-90162005000500003. 
PEDROSO, A. de F.; RODRIGUES, A. de A.; BARIONI JÚNIOR, W.; SOUZA, G.B. de. Fermentation parameters, quality and losses in sugarcane silages treated with chemical additives and a bacterial inoculant. Revista Brasileira de Zootecnia, v.40, p.2318-2322, 2011. DOI: 10.1590/S1516-35982011001100006.

PRYCE, J.D. A modification of Barker-Summerson method for the determination of lactic acid. Analyst, v.94, p.1151-1152, 1969. DOI: $10.1039 /$ an9699401151.

QUEIROZ, O.C.M.; ADESOGAN, A.T.; ARRIOLA, K.G.; QUEIROZ, M.F.S. Effect of a dualpurpose inoculant on the quality and nutrient losses from corn silage produced in farmscale silos. Journal of Dairy Science, v.95, p.3354-3362, 2012. DOI: 10.3168/jds.2011-5207.

SCHMIDT, P. Aditivos químicos e biológicos no tratamento de cana-de-açúcar para alimentação de bovinos. In: JOBIM, C.C.; CECATO, U.; CANTO, M.W. (Ed.). Produção e utilização de forragens conservadas. Maringá: Masson, 2008. p.117-152.

SCHMIDT, P.; MARI, L.J.; NUSSIO, L.G.; PEDROSO, A. de F.; PAZIANI, S. de F.; WECHSLER, F.S. Aditivos químicos e biológicos na ensilagem de cana-de-açúcar. 1. Composição química das silagens, ingestão, digestibilidade e comportamento ingestivo. Revista Brasileira de Zootecnia, v.36, p.1666-1675, 2007. Suplemento. DOI: 10.1590/S1516-35982007000700027.
SIQUEIRA, G.R.; REIS, R.A.; SCHOCKEN-ITURRINO, R.P.; PIRES, A.J.V.; BERNARDES, T.F.; AMARAL, R.C. do. Perdas de silagens de cana-de-açúcar tratadas com aditivos químicos e bacterianos. Revista Brasileira de Zootecnia, v.36, p.2000-2009, 2007. Suplemento. DOI: 10.1590/S151635982007000900008.

SIQUEIRA, G.R.; REIS, R.A.; SCHOCKEN-ITURRINO, R.P.; PIRES, A.J.V.; BERNARDES, T.F.; ROTH, M. de T.P. Queima e aditivos químicos e bacterianos na ensilagem de cana-de-açúcar. Revista Brasileira de Zootecnia, v.39, p.103-112, 2010. DOI: 10.1590/S1516-35982010000100014.

SOUSA, D. de P.; MATTOS, W.R.S.; NUSSIO, L.G.; MARI, L.J.; RIBEIRO, J.L.; SANTOS, M.C. Efeito de aditivo químico e inoculantes microbianos na fermentação e no controle da produção de álcool em silagens de cana-de-açúcar. Revista Brasileira de Zootecnia, v.37, p.1564-1572, 2008. DOI: 10.1590/S151635982008000900007.

TABACCO, E.; PIANO, S.; REVELLOCHION, A.; BORREANI, G. Effect of Lactobacillus buchneri LN4637 and Lactobacillus buchneri LN40177 on the aerobic stability, fermentation products, and microbial populations of corn silage under farm conditions. Journal of Dairy Science, v.94, p.5589-5598, 2011. DOI: 10.3168/ jds.2011-4286.

$\overline{\text { Recebido em } 15 \text { de agosto de } 2012 \text { e aprovado em } 3 \text { de maio de } 2013}$ 